\title{
A governança corporativa e manipulação de informação contábil: mensuração a valor justo nos bancos comerciais
}

\author{
Corporate governance and manipulation of accounting information: \\ measurement at fair value in commercial banks \\ La gobernanza corporativa y manipulación de información contable: \\ mensuración al valor justo en los bancos comerciales
}

\section{Carlos Jorge Fontaínhas Mendes}

Doutorando em Contabilidade no Programa Multi-institucional em Contabilidade da UNB / UFPB / UFRN

Professor da Escola de Negócios e Governação da Universidade de Cabo Verde

Endereço: Rua Rodrigues Ferreira n 45, BL D Apto 1604 Várzea

CEP: 50810-020 - Recife/PE - Brasil

E-mail: fontainhas.carlos@gmail.com

Telefone: (81) 9744-7224

\section{Fátima de Souza Freire}

Doutora em Economia pela Université des Sciences Sociales de Toulouse I, França Professora do Programa Multi-institucional em Contabilidade da UNB / UFPB / UFRN Endereço: Universidade de Brasília (UnB), Faculdade de Administração, Contabilidade e Economia (FACE), Departamento de Ciências Contábeis e Atuárias (CCA)

Bloco B2, $1^{\circ}$ andar, sala B1 - 54/4, CEP: 70910-900 - Brasília/DF - Brasil

E-mail: ffreire@unb.br

Telefone: (61) 3107-0795

Artigo recebido em 14/04/2014. Revisado por pares em 09/06/2014. Reformulado em 17/07/2014. Recomendado para publicação em 28/07/2014 por Sandra Rolim Ensslin (Editora Científica). Publicado em 28/08/2014. 


\title{
Resumo
}

O objetivo do trabalho é verificar se a Governança Corporativa inibe a prática de gerenciamento de resultado no processo de mensuração a valor justo nos bancos comerciais. Foram utilizadas informações das instituições de 125 países, contidas no Bloomberg databases. Conclui-se que (i) são poucos $(26,8 \%)$ aqueles que divulgam em seus relatórios financeiros os ativos avaliados pelo valor justo; (ii) a Governança Corporativa (GC) exerce uma influência preponderante na escolha dos critérios de avaliação dos ativos a valor justo; (iii) enquanto na América Central existe maior possibilidade na manipulação de informação contábil, na Europa ela parece ser com menor frequência.

Palavras-chave: Governança corporativa. Gerenciamento de resultados. Valor justo. Bancos comerciais.

\begin{abstract}
The aim of this work is to verify whether the Corporate Governance practice management inhibits result in the process of measurement at fair value on the commercial banks. It was used information from the institutions in 125 countries, contained in the Bloomberg databases. We conclude that (i) are few $(26.8 \%)$ the ones who reported in their financial reports the assets measured at fair value; (ii) Corporate Governance (CG) has a preponderant influence on the choice of evaluation criteria of assets at fair value; (iii) while in Central America there is a greater possibility in manipulating accounting information, in Europe it seems to be less frequently.
\end{abstract}

Keywords: Corporate governance. Management of results. Fair value. Commercial banks.

\section{Resumen}

El objetivo del trabajo es verificar si la Gobernanza Corporativa inhibe la práctica de gerenciamiento de resultado en el proceso de mensuración al valor justo en los bancos comerciales. Fueron utilizadas informaciones de las instituciones de 125 países, contenidas en el Bloomberg databases. Se concluye que (i) son pocos $(26,8 \%)$ aquellos que divulgan en sus informes financieros los activos evaluados por el valor justo; (ii) la Gobernanza Corporativa (GC) ejerce una influencia preponderante en la elección de los criterios de evaluación de los activos al valor justo; (iii) mientras que en América Central existe mayor posibilidad en la manipulación de información contable, en Europa ella parece ser con menor frecuencia.

Palabras clave: Gobernanza corporativa. Gerenciamiento de resultados. Valor justo. Bancos comerciales. 


\section{Introdução}

Estudos têm demonstrado que parecem existir incentivos econômicos, levando as instituições financeiras à prática de manipulação da informação contábil (SONG, 2008; ALKHADASH; ABDULLATIF, 2009). Com a convergência das normas contábeis e a adoção do valor justo no processo de avaliação de determinados ativos e passivos, surgiu uma possibilidade do gerenciamento de resultados ou da manipulação de informações contábeis. Isso decorre, tendo em conta a existência de graus crescentes de subjetividade nos três níveis de avaliação das contas patrimoniais, propostos pelas Normas Internacionais de Relato Financeiro (IFRS) de número 13 - Fair Value Measurement, bem como a liberdade de os gestores escolherem o nível de avaliação pelo valor justo a ser aplicado em ativos e passivos.

Segundo Song (2008), nos bancos americanos, os determinantes do uso da Fair Value Option (FVO) são motivações oportunistas, admitindo o gerenciamento de resultados, bem como os ajustes nas carteiras de reestruturação. Além disso, devido à forma de utilização do FVO, enquanto as perdas não realizadas são reconhecidas nos balanços, os ganhos não realizados não o são.

Al-Khadash e Abdullatif (2009) analisaram a introdução das IFRS, nos países em desenvolvimento, mais precisamente na Jordânia, concluindo que o desempenho econômico de um banco é geralmente afetado significativamente pela valorização dos instrumentos financeiros avaliados a valor justo. Seguem ainda relatando que há um aumento elevado do lucro por ação, quando ocorre a aplicação do valor justo de instrumentos financeiros. No caso de alguns países em desenvolvimento onde os mercados financeiros são ineficientes como, por exemplo, na Jordânia, a utilização do valor justo de instrumentos financeiros distorce os resultados das empresas, o que permite ludibriar os stakeholders com informações contábeis enganosas.

Segundo Bratten et al. (2013), os bancos com altos níveis de utilização de valor justo empregam a parte discricionária da provisão para perdas de crédito para amortecer ganhos. Além disso, bancos, que utilizam em grau elevado a contabilidade do valor justo, fazem em maior nível Trade off entre tal provisão e tais ganhos e perdas do que aqueles com baixo emprego. Em se tratando ainda de manipulação de resultados, a pesquisa de Dechow et al. (2010) mostra que as empresas ficam mais propensas a relatar maiores lucros quando os ganhos de pré-securitização são baixos ou quando estão abaixo do resultado do ano anterior. Isso indica que gestores usam a flexibilidade disponível nas regras da contabilidade a valor justo para gerenciar ganhos. Nota-se então que a Contabilidade tem normas que admitem aos gestores gerenciar resultados.

Entretanto, a Governança Corporativa constitui um instrumento gerencial muito importante no tocante à diminuição de possíveis manipulações de resultados. A título de exemplo, cita-se o estudo de Ramos e Martinez (2006), explanando que as empresas brasileiras do novo mercado apresentaram menor variabilidade nas acumulações discricionárias (discritionary accruals) do que aquelas que não aderiram ao programa. Nos seus estudos, foi apontada uma correlação entre a propensão do gerenciamento de resultados e as características do conselho de administração, do conselho fiscal, da auditoria independente e da estrutura de propriedade. Concluíram que uma fraca Governança Corporativa aumenta a disposição ou a probabilidade de manipulação de contas.

Segundo Rangel e Andrade (2005), a redução do gerenciamento de resultados e de fraudes está associada à independência e à qualificação dos conselhos de administração. Para 
que os membros venham a compreender melhor o tipo de negócio das empresas e a forma de atuação dos agentes, as organizações devem melhorar seus instrumentos de Governança Corporativa.

Estudos relacionando gerenciamento de resultados e Governança Corporativa em instituições financeiras se mostram importantes, uma vez que, nos bancos comerciais, cerca de $20 \%$ dos ativos são avaliados a valor justo. A forma como essa avaliação é realizada pode ter impactos significativos no valor patrimonial e nos resultados reportados. Além disso, corroborando Kadous, Koonce e Thayer, 2012, a demanda pela transparência alvitra uma informação contábil clara e confiável, representando uma fidelidade e sendo essencial para o aumento da credibilidade das empresas no mercado acionário. Além de que Kraft (2005) já alertava pela necessidade de avanços e melhorias nas técnicas de avaliação da contabilidade do valor justo, bem como de flexibilização das normas contábeis ao longo do tempo, além da implicação de um terceiro agente para validação dos dados avaliados.

Dessa forma, levando em conta as considerações e as constatações acima relatadas, levanta-se a seguinte questão de pesquisa: A Governança Corporativa é um instrumento que contribui para minimizar a prática de manipulação de informação contábil no processo de mensuração a valor justo de ativos nos bancos comerciais? A pesquisa traz contribuições importantes uma vez que permite verificar se existe uma relação entre a eficiência da Governança Corporativa e a prática de manipulação de informação na mensuração a valor justo, dando assim informações mais acuradas à sociedade quanto às interpretações dos resultados apresentados nas demonstrações contábeis.

O presente estudo tem por objetivo verificar se a Governança Corporativa é um instrumento que inibe a prática de manipulação de informação contábil no processo de mensuração a valor justo de ativos nos bancos comerciais nas diversas regiões geoeconômicas. Para isso, têm-se os seguintes objetivos específicos:

a) identificar a propensão dos bancos comerciais de cada região geoeconômica em adotar critérios mais subjetivos, ou menos subjetivos, no processo de mensuração a valor justo dos ativos.

b) identificar, por meio de um índice, o nível de Governança Corporativa dos bancos comerciais dessas regiões.

c) analisar as relações entre o nível de Governança Corporativa e a propensão dos bancos em adotar critérios mais subjetivos, ou menos subjetivos, no processo de mensuração a valor justo dos ativos.

\section{Referencial Teórico}

\subsection{Gerenciamento de Resultado nas Instituições Financeiras e Estudos Correlacionados}

$\mathrm{Na}$ literatura acadêmica, dois trabalhos se destacam quanto à conceituação de gerenciamento de resultado, Schipper (1989) e Healy e Wahlen (1999). Schipper (1989) define o termo como sendo a prática de intervenção proposital no processo de divulgação externa dos relatórios contábeis com a intenção de obter algum ganho privado. Já Healy e Wahlen (1999) argumentam que o gerenciamento de resultados ocorre quando os administradores utilizam julgamento nos relatórios financeiros para ludibriar os stakeholders 
sobre o desempenho econômico da empresa ou para influenciar resultados de contratos que dependem dos números contábeis publicados.

Estudos realizados no exterior e no Brasil apresentam evidências de que os gestores utilizam critérios contábeis para gerenciar resultados, dentre eles destacam-se os trabalhos de Healy, 1985; DeAngelo, 1986; Jones, 1991; DeFond e Jiambalvo, 1994; Perry e Williams, 1994; Teoh, Welch e Wong, 1998; Kasznik, 1999; Paulo et al., 2005; Ramos e Martinez, 2006; Rodrigues et al., 2007; Huang et al., 2009; e Resende e Nakao, 2012. Pesquisas têm dedicado atenção especial às instituições financeiras, quer pela importância no mercado de capitais e sistema financeiro, quer pela importância quantos às questões relacionadas com os stakeholders.

No contexto brasileiro, além dos trabalhos de Fuji, 2004; Zendersky, 2005; Cupertino, 2006; Monteiro e Grateron, 2006; Xavier 2007; e Perlingeiro, 2009 que corroboram os estudos internacionais, destacam-se também trabalhos publicados recentemente.

Gabriel e Corrar (2010) investigam se existe gerenciamento de resultados contábeis no contexto das instituições bancárias no Brasil com foco na conta de títulos e valores mobiliários. Os autores concluíram que os bancos utilizam parte do ajuste ao valor de mercado para gerenciar seus resultados. Como motivação para tal prática, apontam a necessidade de cumprimento dos limites mínimos operacionais e a apresentação de uma situação estável ao longo do tempo para os stakeholders e a autoridade supervisora do sistema financeiro.

Galdi e Câmara (2012) investigam a existência de prática de gerenciamento de resultados nas instituições financeiras brasileiras por meio da realização de operações de securitização. Corroborando a literatura internacional, foram encontradas evidências de que os gestores utilizam a discricionariedade presente nas transações de securitização para suavizar o resultado.

Dantas et al. (2013) desenvolveram um modelo de dois estágios para a identificação da discricionariedade nos resultados com TVM. O modelo proposto apresentou evidências da prática de alisamento de resultados com o uso de TVM, bem como a utilização da classificação em títulos disponíveis para venda nas ações de gerenciamento. Conforme os autores, a validação do modelo proposto contribui para o desenvolvimento de pesquisas sobre o tema com que se preocupam, não apenas em constatar se existe ou não prática de gerenciamento, mas também associá-la a outras variáveis.

\subsection{Evidências de Gerenciamento de Resultados Vinculados ao Valor Justo nas Intuições Financeiras}

Gebhardt et al. (2003) analisaram os efeitos de três conjuntos de regras contábeis para instrumentos financeiros: o IAS anterior ao IAS 39 entrar em vigorar, o US GAAP e o Full Fair Value (FFV) nas demonstrações financeiras dos bancos. Desenvolveram um modelo de simulação que captura as características essenciais de um banco moderno universal, como bancos de investimento e atividades de banco comercial. Efetuaram simulações para diferentes estratégias (totalmente coberto, parcialmente coberto), utilizando dados históricos de períodos de subida e descida das taxas de juro. Os autores concluíram que

- Na utilização do velho IAS um banco totalmente coberto pode apresentar ganhos econômicos de zero em suas demonstrações financeiras. 
- Como no velho IAS existem muitos critérios, os bancos também podem apresentar lucro ou prejuízo.

- Por causa das regras de contabilização de hedge restritivas, os bancos não podem apresentar adequadamente suas atividades de gestão de risco das melhores práticas no âmbito da IAS atual ou US-GAAP.

- Contrariamente às afirmações do setor bancário a Contabilidade baseada no FFV reflete adequadamente a economia das atividades bancárias.

Karaoglu (2005) investiga se os bancos usam vendas de empréstimos e securitizações (empréstimo transferências) para gerenciar o capital regulatório e os ganhos. O autor encontrou evidências que levam às seguintes conclusões:

- Os bancos utilizam os ganhos de transferências de empréstimos para influenciar os ganhos reportados e o capital regulamentar após o controle de outras motivações econômicas.

- Os ganhos podem ser atribuídos tanto a cherry-picking de empréstimos cujos valores de mercado são superiores a seus valores contábeis e também à supervalorização dos lucros retidos que sejam provocados pelo valor justo de mercado, no caso de securitizações.

- O uso da securitização para a gestão das demonstrações financeiras está positivamente associado com o grau de discricionariedade de relatórios financeiros à disposição dos gestores. $\mathrm{O}$ autor enfatiza que as evidências mostram que o capital regulatório parece desempenhar um papel significativo na decisão de transferir empréstimos, enquanto que o gerenciamento de resultados é mais importante no cálculo dos ganhos condicionais reportados sobre a realização de uma transferência, sobretudo no caso da securitização.

Song (2008) investiga três questões relacionadas a Fair Value Ooption (FVO) da FAS 159 nos bancos americanos. Em primeiro lugar, examina os fatores que estão associados à adoção do FVO. Em segundo lugar, verifica se as empresas utilizam o FVO como pretendido pelo FASB: reduzir a volatilidade dos lucros e simplificar tratamentos de contabilização de hedge. Por fim o autor analisa o value relevance dos ganhos e perdas não realizados e reconhecidos devido ao FVO. O autor concluiu que os determinantes do uso da FVO estão associados a motivações oportunistas, tais como gerenciamento de resultados e carteiras de reestruturação. Encontrou também evidências de que os bancos (1) exploram a prestação de ajuste de transição permitido pelo FAS 159 para remover títulos disponíveis para venda, com perda de posições sem relatar as perdas em ganhos; e (2) divulgam lucros maiores do que os ganhos de destino, administrando os ganhos por meio do FVO. Por fim, constatou-se que as perdas não realizadas são reconhecidas devido ao FVO, ao passo que os ganhos não realizados não são. O autor afirma que, no geral, o FVO parece induzir efeitos indesejáveis.

Al-Khadash e Abdullatif (2009) analisaram a introdução das Normas Internacionais de Relato Financeiro (IFRS) nos países em desenvolvimento, mais precisamente na Jordânia. O estudo tem como objetivo fornecer evidências sobre o efeito da mensuração a valor justo dos instrumentos financeiros no desempenho financeiro (lucro por ação) das empresas. Os pesquisadores fazem uma comparação dos resultados contábeis reportados sob a avaliação de instrumentos financeiros a valor justo e a custo histórico. O estudo conclui que o desempenho financeiro de um banco é geralmente afetado significativamente pela valorização dos 
instrumentos financeiros avaliados a valor justo. Há também um aumento extremamente elevado do lucro por ação na aplicação do valor justo na avaliação dos instrumentos financeiros, em comparação com quando os ganhos são calculados sem adicionar os ganhos e as perdas. Os autores afirmam que, no caso de alguns dos países em desenvolvimento como a Jordânia, onde os mercados financeiros são ineficientes, a utilização da Contabilidade baseada no valor justo para instrumentos financeiros pode distorcer os resultados das empresas e enganar os usuários das demonstrações contábeis.

Bratten et al. (2013), baseados em investigações anteriores, constataram que os bancos utilizam as Provisões para Perdas de Crédito (PPC) e ganhos e perdas realizados em vendas de investimentos para gerenciar lucros divulgados. Os autores investigam se a frequência da utilização dessas ferramentas de gerenciamento de resultados pelos bancos depende da sua exposição à Contabilidade pelo justo valor. Eles defendem que os bancos com maior exposição à Contabilidade a valor justo são mais capazes de substituir o gerenciamento de resultados baseado no PPC pelo gerenciamento de resultados baseado em transação (ou seja, o gerenciamento de resultados alcançados por cronometrar a realização de ganhos / perdas). Verificam também em que medida a especialização do auditor afeta no uso dessa ferramenta de gerenciamento de resultados. Concluíram que os bancos com altos níveis de utilização de valor justo utilizam a parte discricionária da Provisão para Perdas de Crédito (PPC) para suavização de seus ganhos, em menor grau do que outros bancos. Além disso, os bancos com alto níveis de utilização de valor justo fazem Trade off entre a utilização da PPC e a utilização de ganhos e perdas, em maior grau que os outros bancos. Os autores também encontraram evidências consistentes que comprovam que quanto mais especializados são os auditores mais se mitiga da utilização da parte discricionária do PPC e do timing de ganhos e perdas para realização de suavização de resultados.

Laghi et al. (2012), tendo como finalidade verificar se as soluções propostas nas normas adotadas pela Contabilidade do valor justo realmente melhoram o nível de disclosure e a utilidade das informações para os investidores, analisam o nível real da transparência e da utilidade da hierarquia de valor justo nos bancos americanos e nos italianos. Os autores concluíram que

- O valor justo no Nível 3 é o critério mais subjetivo na mensuração de instrumento financeiros, mostra baixa relevância em bancos dos Estados Unidos e muito menos relevância na Itália.

- A divulgação na hierarquia do valor justo não é amplamente adotada; considerando uma amostra potencial de mais de 2.500 bancos cotados, apenas 281 divulgam atualmente em três diferentes níveis de valor justo, conforme solicitado pelos princípios contábeis (IFRS 7 e SFAS 157).

- Os resultados da análise de regressão mostram que as variáveis investigadas capitalização de mercado, o lucro líquido e três níveis de valor justo - são bastante associados, nos pressupostos específicos, mas eles não oferecem informação única e clara para os investidores em termos de utilidade para a sua estratégia de alocação de capital.

Como síntese, os autores afirmam que, mesmo se os princípios da hierarquia de valor justo permitirem melhor compreensão sobre as tendências em valor e composição das carteiras de instrumentos financeiros dos bancos, eles sofrem de duas limitações principais: (i) 
problemas de subjetividade na estimativa de valor; e (ii) volatilidade de curto prazo em resultados devido a mudanças em variáveis macroeconômicas.

Dechow et al. (2010) investigam se os gerentes usam a discrição proporcionada pelas regras contábeis do valor justo para gerenciar resultados referentes aos de ganhos de securitização de Ativos. A pesquisa teve três objetivos principais: (i) determinar se os gerentes usam o alto grau de julgamento e discrição obtido por meio da implementação de regras de Contabilidade de valor justo para relatar maiores ganhos para melhorar a percepção de seu desempenho; (ii) examinar se a compensação dos CEOs é menos sensível aos ganhos de securitização de outro ganhos; e (iii) investigar se os conselhos de administração desempenham um papel de monitoramento para determinar o tamanho dos ganhos relatados ou na determinação da sensibilidade da remuneração do $C E O$ aos ganhos de securitização relatados. Quanto ao primeiro objetivo, os resultados evidenciaram que as empresas são mais propensas a relatar maiores ganhos quando os ganhos pré-securitização são baixos ou estão abaixo do nível do ano anterior. Sugerem que os gerentes usam a flexibilidade disponível ao aplicar regras de Contabilidade de valor justo para gerenciar ganhos. Quanto ao segundo objetivo, os resultados mostram que as taxas de desconto são mais baixas, em média, quando as empresas relatam perdas de securitização, em vez de ganhos de securitização. Essas taxas de desconto mais baixas reduzem o tamanho da perda relatado. Encontrou-se também o agrupamento das taxas de desconto escolhido em $10 \%$ e $12 \%$, sugerindo que a escolha da taxa de desconto de gestão pode ser arbitrária. Os autores descobriram também que as empresas que selecionam altas taxas de desconto (mais de 18\%) tendem a relatar grandes ganhos ou perdas extremamente grandes, sugerindo que a escolha de altas taxas de desconto pode ser motivada por incentivos de plano de bônus. Quanto ao terceiro objetivo, os resultados evidenciaram que a compensação $C E O$ é sensível aos ganhos relatados e que os ganhos parecem ser tratados como um componente regular da remuneração.

\subsection{Governança Corporativa como Ferramenta Mitigadora de Gerenciamento de Resultado}

O Instituto Brasileiro de Governança Corporativa (IBGC, 2010) define Governança Corporativa como "um sistema pelo qual as organizações são dirigidas, monitoradas e incentivadas, envolvendo os relacionamentos entre proprietários, Conselho de Administração, Diretoria e órgãos de controle". No entanto, outros autores definiram esse conceito. Para Silveira (2004), a Governança Corporativa pode ser compreendida como um conjunto composto por mecanismos de incentivo e de controle, internos e externos, que visam minimizar os custos decorrentes do problema de agência. Segundo Shleifer e Vishny (1997), a Governança Corporativa relaciona-se com as formas pelas quais investidores podem ter a certeza que terão o retorno por seus investimentos. Zingales (1998) define a Governança Corporativa como sendo um complexo de restrições que moldam a barganha ex post sobre as quase rendas geradas no curso da relação das entidades. Gillan e Starks (1998) enfatizam que a Governança Corporativa pode ser definida como o sistema de leis, regras e fatores que conduzem as operações em uma companhia.

Como ferramenta mitigadora de gerenciamento de resultado, a Governança Corporativa tem sido estudada por vários autores procurando testar e compreender essa relação. Os trabalhos de Dechow et al. (1996); Leuz et al. (2003); Chang et al. (2007); e Cornett et al. (2009) encontraram correlação negativa entre esses dois construtos. No cenário brasileiro, destacam-se os trabalhos de Martinez (2001); e de Ramos e Martinez (2006), que 
corroboraram os estudos internacionais, possibilitando assim inferir que níveis mais elevados de governança realmente podem mitigar o comportamento oportunista por parte dos gestores $\mathrm{e}$, com isso, reduzir o gerenciamento de resultados.

Por outro lado, o estudo de Shah et al. (2009) que analisa a relação entre a qualidade de Governança Corporativa e gerenciamento de resultados no mercado paquistanês verificou a presença de relação positiva entre Governança Corporativa e gerenciamento de resultados. Esse resultado não corroborara os estudos anteriores, o autor justifica esse resultado pouco convencional devido à fase de transição por meio do qual as empresas paquistanesas estão passando após a promulgação do código de Governança Corporativa, em 2002, que criou uma tendência de acumulações discricionárias como medida de aversão ao risco. $\mathrm{O}$ trabalho de Erfurth e Bezerra (2013) que investiga essa relação no mercado brasileiro para diferentes níveis de Governança Corporativa das empresas listados na Bovespa também não encontrou evidências de que níveis diferenciados de governança resultem em menores práticas de gerenciamento de resultados através dos accruls discricionário. Contrariando esse resultado e corroborando os estudos anteriores, o trabalho de Piccoli et al. (2014) apresentou evidências de que a discricionariedade na divulgação de prejuízos e de quedas nos lucros é mais pronunciada nas empresas tradicionais, mostrando que as práticas de Governança Corporativa preconizadas por empresas pertencentes ao Novo Mercado mitigam, mas não impedem a discricionariedade. Os autores concluem que o gerenciamento de resultado é mais empregado para evitar a divulgação de prejuízos do que para evitar a divulgação de queda nos lucros. $\mathrm{O}$ trabalho de Santos et al. (2011), realizado na indústria brasileira de capital aberto no setor de siderurgia e metalurgia, também apresentou evidências de que a Governança Corporativa é um contra incentivo ao gerenciamento de resultado no que se refere a decisões operacionais relativas a despesas com vendas, despesas gerais e administrativas.

Além dos estudos que analisam os níveis de Governança Corporativa, outros estudos analisam o mecanismo interno de Governança Corporativa, o papel dos auditores e dos conselhos. Xie e Dadlf (2001) examinam o papel do conselho de administração, do conselho fiscal e da comissão executiva na prevenção de gerenciamento de resultados. Concluem que a atividade do conselho e do comitê de auditoria e a sofisticação financeira dos seus membros podem ser fatores importantes na limitação da propensão dos gerentes a se envolver em gerenciamento de resultados. Gonzalez e Meca (2014) analisam a relação entre os mecanismos internos de Governança Corporativa e gerenciamento de resultados no contexto latino-americano. Os resultados mostraram que o papel dos auditores externos é limitado e que os conselhos são mais ativos no monitoramento dos insiders, reduzindo a práticas de gerenciamento de resultado. Os autores concluíram ainda que a concentração da propriedade pode ser um mecanismo que reduz práticas de gerenciamento de resultado somente quando a propriedade dos principais acionistas é moderada.

No contexto brasileiro destacam-se os trabalhos de Martinez et al. (2010) que investigam como as características do Conselho de Administração e dos Auditores Independentes estão correlacionadas com a propensão para a prática de gerenciamento de resultados no Brasil. Os resultados indicaram que a tolerância para earnings management pode ser explicada pelo perfil do Conselho de Administração. Adicionalmente, os testes indicaram mais permissividade das empresas de auditoria nacionais à prática de earnings management do que seus pares de origem internacional. Barros et al. (2013) investigaram se os mecanismos Governança Corporativa comportam-se como inibidores do gerenciamento de resultados contábeis. Observou-se que a intensidade de gerenciamento de resultados é menor 
em empresas que apresentam presença mais marcante de atributos de Governança. Conforme os autores, tais resultados corroboram as discussões sobre a presença de um trade-off entre estruturas de Governança Corporativa e escolhas contábeis direcionadas a gerenciar resultados contábeis.

Com a convergência às normas internacionais de Contabilidade e a adoção do FAS 157, abriu-se a possibilidade para novas formas de gerenciamento de resultado, que não sejam por meio dos accruals, mas devido à subjetividade no processo de mensuração a valor justo, possibilitando assim novas pesquisas com o objetivo de verificar as relações entre os mecanismos de Governança Corporativa e o processo de mensuração e avaliação a valor justo.

Fiechter e Meyer (2008) examinaram os mecanismos de Governança Corporativa que reduziram a discrição nas provisões para perdas com empréstimos (LLP) e estimativas de valor justo para gerenciar o lucro nos bancos durante a crise financeira de 2008. Os autores não encontraram evidências consistentes de que melhores mecanismos de Governança Corporativa efetivamente reduzem o uso discricionário de LLP e a mensuração a valor justo no Nível 3 para suavizar ganhos.

Song (2010) constatou que o value relevance do valor justo no Nível 1 e no Nível 2 é maior que a do Nível 3. Encontraram evidências de que a value relevance do valor justo, especialmente do Nível 3 é maior para as empresas com uma forte governança corporativa. Os autores concluíram que os resultados da pesquisa reforçam a relevância da mensuração do valor justo sob FAS 157, e que os mecanismos de Governança Corporativa mais fracos podem reduzir a relevância de tais medidas.

Bhat (2013) examina as relações entre as divulgações de gestão de risco, governança e os preços do mercado para Ganhos e Perdas de Valor Justo (GPVJ) para holdings de bancos comerciais no mercado norte-americano. $\mathrm{O}$ autor encontrou evidências de que os bancos com uma forte Governança Corporativa divulgam mais sobre suas práticas de gestão de risco e que o preço do mercado para GPVJ aumenta com o nível de divulgação. Os resultados demonstraram que o efeito da divulgação sobre os preços do mercado para os bancos com ativos de risco, e para os bancos com fraco desempenho é mais evidente para em períodos de crise. $\mathrm{O}$ autor concluiu que as evidências sugerem que os participantes do mercado percebam os GPVJ dos bancos com alta divulgação e forte Governança Corporativa como sendo mais relevante e confiável.

No contexto brasileiro, Umbelino et al. (2007) investigam o nível de evidenciação do valor justo dos instrumentos financeiros dos bancos listados no Novo Mercado e nos diferentes níveis de Governança Corporativa da Bovespa. Os autores constataram que o grau de evidenciação do valor justo dos instrumentos financeiros entre os bancos listados no Novo Mercado não foi maior que o de Nível 2 e nem prevaleceu em sua totalidade sobre a evidenciação do valor justo dos instrumentos financeiros do Nível 1. Já o nível de divulgação entre os bancos de Governança Corporativa foi maior que os bancos não listados no Novo Mercado e nos Níveis 1 e 2 de Governança Corporativa. Os resultados também demonstraram que os bancos estatais apresentaram um nível de evidenciação abaixo daqueles bancos mais tradicionais e que os requisitos mínimos da Circular $n^{\circ}$ 3068/2001 do Banco Central do Brasil foram atendidas quase em sua totalidade, embora com maior abrangência em alguns casos. 


\section{Procedimentos Metodológicos}

\subsection{População e Plano Amostral}

Para viabilizar a pesquisa, foi tomado como população o conjunto dos bancos comercias e bancos múltiplos listados na Bloomberg database que exerceram ininterruptamente suas atividades de 2008 a 2012. Como amostra, foram selecionados os bancos que evidenciaram nos seus relatórios financeiros e nas notas explicativas o valor justo dos ativos e passivos de forma detalhada, conforme sugere o IFRS7 que originou, no Brasil, o CPC 40 (R1) - Instrumentos Financeiros: Evidenciação - que, no seu paragrafo 25, estabelece que "[...] para cada classe de ativo financeiro e passivo financeiro a entidade deve divulgar o valor justo daquela classe de ativos e passivos de forma que permita ser comparada com o seu valor contábil [...]". Assim, a pesquisa teve por base dados secundários anuais e trimestrais de 736 bancos comercias e múltiplos de diversas nacionalidades. Os bancos que compõem a amostra são agrupados por regiões geoeconômicas, quais sejam: América do Norte, América Central, América do Sul, Europa, Leste Europeu, África, Oriente Médio, Ásia e Austrália. Tomou-se como data inicial para a pesquisa dezembro de 2008 e a data limite dezembro 2012.

\subsection{Identificação das Variáveis}

A análise de dados, baseou-se na metodologia utilizada por Huang et al. (2009) para detectar quais os incentivos que contribuíram para o gerenciamento dos resultados no processo de mensuração a valor justo nos bancos americanos durante o período da crise financeira de 2008. Como proxi para gerenciamento de resultados, tomou-se a proporção dos ativos avaliados no Nível 1 em relação ao total dos ativos avaliados a valor justo.

O IFRS 13 - Fair Value Measurement determina três níveis para mensuração a valor justo. No Nível 1, requer o uso de preços listados num mercado ativo para os ativos e passivos idênticos; no Nível 2, requer o uso de preços listados (de cotação) para ativos e passivos semelhantes em mercados ativos; e no Nível 3, requer o uso de técnicas de avaliação uma vez que não existe um mercado ativo. Conforme Stephen (2007), a mensuração do Valor Justo em três níveis de "entradas" para determinar o preço de mercado caracteriza-se por níveis crescentes de subjetividade, sendo que no Nível 1 a subjetividade é praticamente nula. No entanto, para usar esse nível, é necessário a entidade ter acesso imediato ao mercado (IUDÍCIBUS; MARTINS, 2007).

Já no Nível 2, observa-se alguma subjetividade, uma vez que existem questões relacionadas com a integridade dos gestores. Mesmo os gestores honestos levam a um viés subjetivo em decorrência do otimismo em suas avaliações. A competência e a independência dos auditores, dos avaliadores e dos conselhos de administração também devem ser avaliadas, juntamente com a eficácia dos controles (STEPHEN, 2007). Iudícibus e Martins (2007), destacam que, nos ajustes para o Nível 2, os preços irão variar dependendo de fatores específicos do ativo ou do passivo que incluem a condição ou a localização do bem, o volume e nível de atividade nos mercados em que os preços são observados.

No Nível 3, existe um maior grau de subjetividade uma vez que o valor justo baseado em uma estimativa do preço de mercado (em vez de valor-em-uso), "não observáveis" permite que refletem os pressupostos próprios da entidade que relata sobre os pressupostos que os participantes no mercado utilizariam na precificação do ativo ou passivo (STEPHEN, 2007). 
Conforme Škoda e Bilka (2012), a mensuração a valor justo possibilita a manipulação dos preços por parte das empresas, devido (i) à indefinição dos procedimentos de mensuração que cria brechas para desvios de preços; (ii) a fatores como a ineficiência do mercado, a irracionalidade do investidor, o viés comportamental ou os problemas de arbitragem que podem fazer com que as estimativas do mercado sejam desviadas, produzindo desse modo informações enganosas aos usuários das informações contábeis.

Verifica-se assim que no Nível 1 não existe a possibilidade de discricionariedade, uma vez que os preços são cotados. Já nos Níveis 2 e 3, podem ser realizados ajustes nos preços permitindo atos discricionários. Dessa forma, quanto maior a proporção de ativos avaliados no Nível 1 menores são as chances de gerenciamento de resultados.

Geralmente os estudos realizados no Brasil têm utilizado como métrica para Governança Corporativa a classificação de acordo com os níveis de Governança Corporativa junto à Bovespa. Como exemplo, destacam-se os trabalhos de Erfurth e Bezerra (2013), Almeida-Santos et al. (2011) e Ramos e Martinez (2006). Essa métrica classifica as empresas em quatro níveis: Nível 0 - não aderência de prática de Governança Corporativa junto à Bovespa; Nível 1 - aderência de prática de Governança Corporativa junto à Bovespa comprometendo-se, principalmente, com melhorias na prestação de informações no mercado e com a dispresão acionária; Nível 2 - aderência de prática de Governança Corporativa junto à Bovespa adotando um conjunto mais amplo de práticas de governança e direitos adicionais para os acionistas minoritários; Nível 3 - Novo Mercado, empresas que ingressaram no mercado de capitais após a criação do Novo Mercado pela Bovespa em 2000.

Outras métricas têm sido utilizadas com menor frequência. $\mathrm{O}$ trabalho de Martinez (2010) usou como métrica de boas práticas de Governança Corporativa observando as sugestões constantes nas Cartilhas da CVM e do IBGC. Barros et al. (2013) utilizaram o índice amplo proposto por Leal e Carvalhal-da-Silva (2005). Nessa métrica, o Índice de Governança Corporativa (ICG) é apresentado na forma de rating variando de 0 a 15 ou convertido em percentual variando de $0 \%$ a $100 \%$. Quanto maior o rating ou percentual do IGC mais elevada será sua estrutura de Governança Corporativa. Na presente pesquisa, utilizou-se como métrica para Governança Corporativa o índice de avaliação da Bloomberg database, que varia de 0 a 100 . Quanto maior a pontuação, maior é o nível de Governança Corporativa da empresa.

\subsection{Instrumentos de Análise de Dados}

Estatística Descritiva - Tem como objetivo analisar a propensão dos bancos em adotar critérios mais subjetivos ou menos subjetivos no processo de mensuração a valor justos dos ativos e passivos, assim como as medidas de tendência central do índice de Governança Corporativa.

Análise de Correlação de Pearson - A análise de correlação tem como objetivo averiguar a força do relacionamento entre o nível de subjetividade na mensuração dos ativos a valor justo e o nível de governança, possibilitando assim constatar se existe evidências de que a Governança Corporativa inibe a discricionariedade dos gestores na escolha de critérios mais subjetivos no processo de avaliação de ativos a valor justo.

Análise de Regressão - A análise de regressão tem como a finalidade testar a significância do nível de Governança Corporativa com relação às escolhas dos critérios de 
mensuração a valor justo e verificar se as médias do índice de Governança Corporativa para cada região geoeconômica são estatisticamente diferentes, conforme as equações 1 e 2 .

Grande parte dos casos de manipulação de informações contábeis é explicada geralmente pela Teoria Contratual da Firma e pela Teoria da Agência. Nesse contexto, a Teoria Contratual da Firma parte da premissa de que o administrador escolherá procedimentos contábeis que maximizem sua utilidade esperada (SUNDER, 1997).

No caso da mensuração de ativos a valor justo, levando em consideração que os Níveis 1, 2 e 3 apresentam graus crescentes de subjetividade (STEPHEN, 2007), quanto maior o grau de subjetividade na avaliação de um elemento patrimonial mais a escolha tenderá a recair em um valor que satisfaça aos interesses particulares dos envolvidos.

Havendo possibilidade de escolher que critério utilizar, espera-se que os gestores dos bancos tendem a dar preferência aos Níveis 2 e 3 no processo de mensuração de ativos a valor justo. Por conseguinte, a avaliação dos ativos no Nível 1, que não permite gerenciamento de resultado, acontece em decorrência das ações de monitoramento da Governança Corporativa. Sendo assim, tomamos como variável dependente o percentual de ativos e passivos avaliado no Nível 1, e como variável independente a efíciência das ações de fiscalização da Governança Corporativa, tendo como proxy o índice de Governança Corporativa. A formulação geral do modelo fica assim definida:

$$
Y_{\mathrm{s}, \mathrm{t}}=\boldsymbol{\beta}_{\mathbf{0}}+\boldsymbol{\beta}_{1} I G C_{\mathrm{s}, \mathrm{t}}+\varepsilon_{\mathrm{s}, \mathrm{t}}
$$

onde: $Y=$ Proporção dos ativos e passivos mensurados no Nível 1 em relação ao total dos ativos e passivos mensurados a valor justo; $I G C=$ Índice de Governança coorporativa; $\boldsymbol{\beta}_{\mathbf{0}}=$ Coeficientes linear; $\boldsymbol{\beta}_{\mathbf{1}}=$ Coeficientes angulares; $\varepsilon_{\mathrm{s}, \mathrm{t}}=$ Termo de erro.

Para verificar se as médias do índice de Governança Corporativa das regiões geográficas são estatisticamente diferentes, foi utilizado o modelo de regressão linear sem intercepto. A formulação geral do modelo fica assim definida:

$$
Y_{\mathrm{s},}=\boldsymbol{\beta}_{1} R E G+\varepsilon_{\mathrm{s}, \mathrm{t}}
$$

Onde: $Y_{\mathrm{s}}=$ Índice de Governança Corporativa; $R E G=$ Regiões Geoeconômicas (variável dummy); $\boldsymbol{\beta}_{\mathbf{1}}=$ Coeficientes angulares; $\varepsilon_{\mathrm{s}, \mathrm{t}}=$ Termo de erro

\section{Resultados}

\subsection{Estatística Descritiva}

Como se pode ver na Tabela 1 , dos 2747 bancos comerciais e múltiplos cadastrados na Bloomberg databases apenas 736 (26,8\%) divulgam dados relativos à mensuração a valor justo. Apesar de a IFRS7 estabelecer que as informações sobre o processo de mensuração a valor justo seja um discluosure obrigatório, a grande maioria dos bancos não divulgam essas informações. Mesmo mercados mais maduros como os da América do Norte e os da Europa apresentam um número relativamente pequeno $(50,8 \%$ e $13,1 \%$, respetivamente) de bancos que cumprem o que a norma estabelece. 
A América do Sul é onde há maior relação de bancos que não divulgam essas informações. Das 91 instituições listadas na base de dados, apenas 5 (5,5\%) divulgam informações da avaliação de ativos e de passivos a valor justo. Outro dado que chama muita atenção diz respeito à América Central e ao Oriente Médio; apesar de não serem considerados mercados tão maduros como os da Europa, apresentaram uma relação superior $(15,4 \%$ e $17,1 \%$, respetivamente) de bancos que divulgam as informações exigidas no IFRS 7.

Tabela 1 - Bancos que Divulgam Informações Sobre Mensuração a Valor Justo por Regiões

\begin{tabular}{|c|c|c|c|c|c|}
\hline & \multirow{2}{*}{ Regiões } & \multirow{2}{*}{$\begin{array}{c}\text { Número } \\
\text { Países }\end{array}$} & \multirow{2}{*}{$\begin{array}{c}\text { Bancos } \\
\text { Listados } \\
\end{array}$} & \multicolumn{2}{|c|}{ Valor Justo } \\
\hline & & & & $\mathbf{n}$ & $\%$ \\
\hline A & América do Norte & 3 & 1312 & 667 & 50,8 \\
\hline $\mathrm{B}$ & América Central & 13 & 52 & 8 & 15,4 \\
\hline $\mathrm{C}$ & América do Sul & 9 & 91 & 5 & 5,5 \\
\hline $\mathrm{D}$ & Europa & 25 & 252 & 33 & 13,1 \\
\hline $\mathrm{E}$ & Leste Europeu & 16 & 317 & 1 & 0,3 \\
\hline $\mathrm{F}$ & Àfrica & 23 & 102 & 0 & 0,0 \\
\hline G & Médio Oriente & 12 & 123 & 21 & 17,1 \\
\hline $\mathrm{H}$ & Àsia e Australia & 24 & 498 & 1 & 0,2 \\
\hline & Total & 125 & 2747 & 736 & 26,8 \\
\hline
\end{tabular}

Fonte: Dados da pesquisa.

Os bancos dos países que compõem o Leste Europeu, a África, a Ásia e a Austrália praticamente não divulgaram informações sobre o valor justo na base de dados utilizado na pesquisa.

Na Tabela 2, são apresentados os valores médios do índice de Governança Corporativa dos bancos das regiões pesquisadas, a base de dados utilizada na pesquisa não dispõe desse indicador para as regiões E, F, G e H. Por conseguinte, a análise se limitou à América do Norte, à América Central, à América do Sul e à Europa.

\section{Tabela 2 - Valor Médio do Indice de Governança Cooprativa por Região}

\begin{tabular}{c|l|c|c|c|c}
\hline \multicolumn{2}{l|}{ Regiões } & $\mathbf{2 0 0 8}$ & $\mathbf{2 0 0 9}$ & $\mathbf{2 0 1 0}$ & $\mathbf{2 0 1 1}$ \\
\hline A & América do Norte & 49,14 & 50,08 & 51,51 & 50,88 \\
B & América Central & 41,52 & 44,64 & 30,36 & 30,36 \\
C & América do Sul & 53,57 & 47,02 & 66,07 & 73,21 \\
D & Europa & 51,28 & 52,05 & 52,89 & 51,82 \\
E & Leste Europeu & -- & -- & -- & -- \\
F & Àfrica & -- & -- & -- & - \\
G & Médio Oriente & -- & -- & -- & - \\
H & Àsia e Australia & -- & -- & -- & - \\
\hline
\end{tabular}

Fonte: Dados da pesquisa. 
Observa-se que, na América do Norte e na Europa, os valores médios do índice de Governança Corporativa têm mantido constante variando entre 49,14 e 50,88, e 51,28 e 52,89 pontos, respetivamente. Já a América Central apresenta uma tendência decrescente saindo de 41,52 pontos em 2008 para 30,36 pontos em 2011. A América do Sul apresentou queda entre os anos de 2008 a $2009(53,57$ - 47,02) e a partir dessa data apresentou uma tendência crescente atingindo 73,21 no final do período em análise.

De forma geral, a América do Sul apresentou os maiores índices de Governança Corporativa e a América do Norte os menores, resultado surpreendente, visto que, sendo o mercado da América do Norte o mais maduro, se espera melhor estruturação dos mecanismos de Governança Corporativa. No entanto, esse resultado talvez possa ser justificado, pelo fato de a existência de um grande número de pequenos bancos no mercado norte-americano não necessitarem de mecanismos sofisticados de Governança Corporativa.

Quanto à mensuração dos ativos a valor justo, como se pode observar na Figura 1, existe uma preferência geral em avaliar os ativos nos níveis mais subjetivos. Esse comportamento por parte dos bancos está de acordo com o esperado e vai ao encontro da premissa da teoria contratual da firma defendida por Sunder (1997), visto que permite a possibilidade de os bancos manipularem os dados e apresentarem relatórios financeiros de acordo com seus interesses.

Figura 1 - Proporção dos Ativos Avaliados a Valor Justo por Região

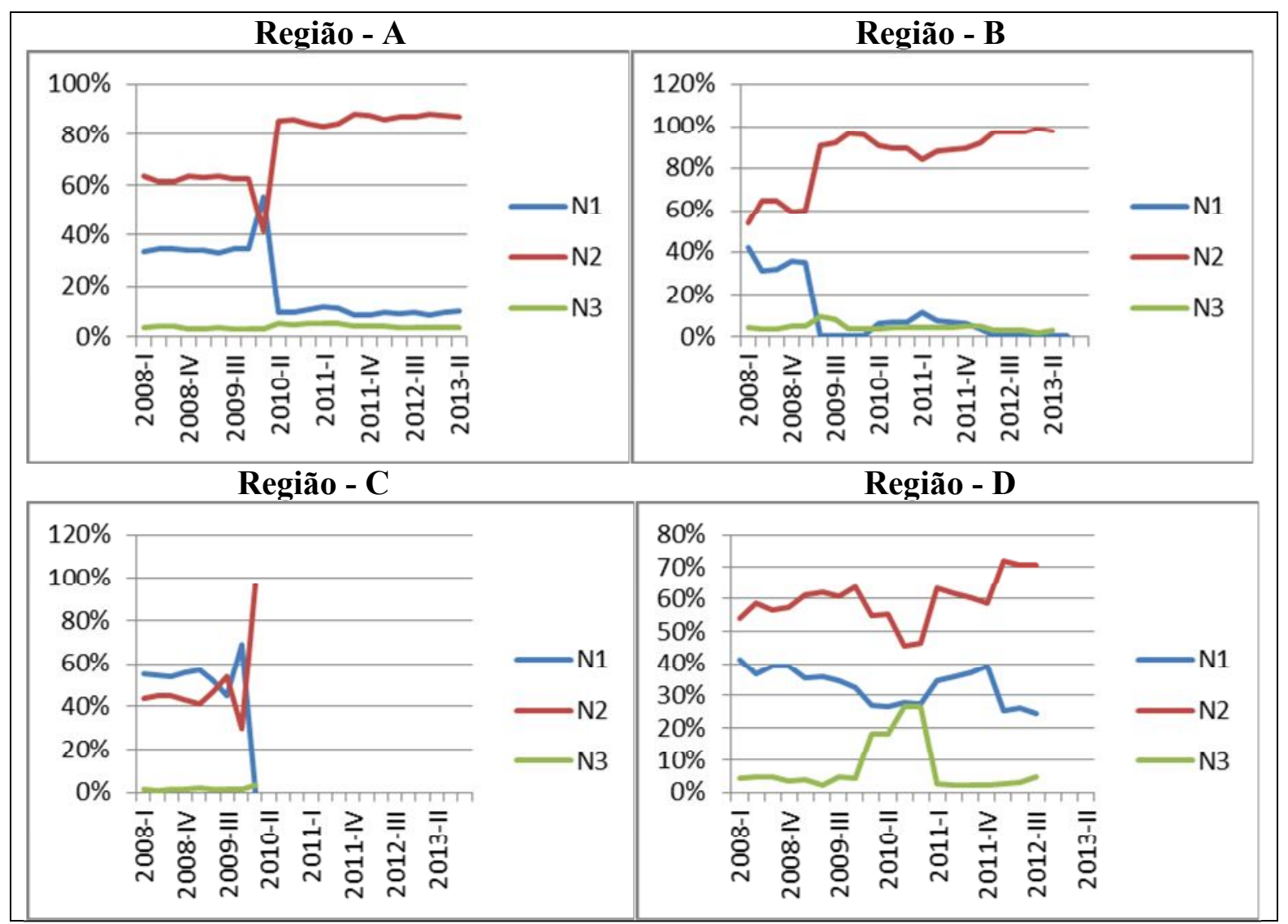

Fonte: Dados da pesquisa. 
Percebe-se também que houve uma mudança na proporção dos ativos avaliados a valor justo em todas as regiões a partir do terceiro período de 2009 com aumentos nos ativos avaliados no Nível 2 e redução nos avaliados no Nível 1. Esse comportamento pode ter como causa as turbulências e instabilidades provocadas pela crise financeira de 2008 .

As regiões A e B apresentam comportamento semelhante. No início do período, cerca de $60 \%$ dos ativos eram avaliados no Nível 2, e 40\% no Nível 1 . No final do período em análise, cerca de $90 \%$ dos ativos foram avaliados no Nível 2, e apenas cerca de $10 \%$ no Nível 1. Os ativos avaliados no Nível 3 permaneceram constantes sempre abaixo de $5 \%$.

$\mathrm{Na}$ região $\mathrm{C}$, diferentemente das regiões $\mathrm{A}$ e $\mathrm{B}$, a maioria dos ativos foi avaliada no Nível 1 no início do período (55\%), e apenas cerca de $40 \%$ dos ativos foram avaliados no Nível 2. Já no ano de 2010, a maioria dos ativos foi avaliada no Nível 2 (cerca de 99\%), e cerca de 1\% no Nível 3. Praticamente não houve ativos avaliados no Nível 1.

$\mathrm{Na}$ região $\mathrm{D}$, contrariamente ao que ocorreu nas outras regiões, não houve mudança brusca na escolha dos critérios de avaliação dos ativos, mas, sim, uma tendência crescente ao longo do período para os ativos avaliados no Nível 2 e uma tendência decrescente para os ativos avaliados no Nível 1. Os ativos avaliados no Nível 3 apresentaram maior oscilação que nas demais regiões, atingindo um pico de cerca de 30\% no quarto período de 2010.

\subsection{Análise de Correlação e Regressão}

Na Tabela 3, são apresentados os coeficientes de correlação. Pode-se constatar que a Governança Corporativa exerce uma influência na escolha dos critérios de avaliação a valor justo, visto que existe uma correlação positiva $(0,1631)$ entre o índice de Governança Corporativa (GC) e o Nível 1 de subjetividade o que evidencia que quanto mais eficiente a Governança Corporativa maior quantidade de ativo é avaliada no Nível 1 (não permite manipulação de informação).

Tabela 3 - Coeficientes de Correlação

\begin{tabular}{cccc|c}
\hline $\mathrm{N} 1$ & $\mathrm{~N} 2$ & $\mathrm{~N} 3$ & $\mathrm{GC}$ & \\
\hline 1 & $-0,901$ & $-0,0201$ & 0,1631 & $\mathrm{~N} 1$ \\
& 1 & $-0,4156$ & $-0,2154$ & $\mathrm{~N} 2$ \\
& & 1 & 0,1344 & $\mathrm{~N} 3$ \\
& & & 1 & $\mathrm{GC}$ \\
\hline
\end{tabular}

Fonte: Dados da pesquisa.

Com relação ao Nível 2, existe uma correlação negativa $(-0,2154)$ evidenciando que quanto menor o nível de Governança Corporativa maior quantidade de ativo é avaliado no Nível 2 (permite manipulação de informação). Esses resultados corroboram as pesquisas sobre Governança Corporativa e gerenciamento de resultados, realizadas tanto no Brasil (MARTINEZ, 2001; RAMIRO; MARTINEZ, 2006; GOULART, 2007; UMBELINO et al., 2007; PICCOLI et al., 2014; SANTOS et al., 2011), como no cenário internacional (DECHOW et al., 1996; LEUZ et al., 2003, CHANG et al., 2007, CORNETT et al., 2009; FIECHTER; MEYER, 2008; SONG, 2010; BHAT, 2013).

$\mathrm{Na}$ Tabela 4, podemos verificar que a Governança Corporativa apresentou coeficiente com alto nível de significância $(0,00025)$, evidenciando que exerce uma influência preponderante na escolha do critério de Nível 1 de subjetividade para avaliação dos ativos. 
Tabela 4- Estimativas "Pooled $O L S$ " variável depenndente N1

\begin{tabular}{lccccc}
\hline \multicolumn{1}{c}{ Variável } & Coeficiente & Erro Padrão & estatística- $t$ & $p$-valor & \\
\hline const & $-0,111125$ & 0,0530036 & $-2,0965$ & 0,03654 & $* *$ \\
$\mathrm{GC}$ & 0,00379682 & 0,00102844 & 3,6918 & 0,00025 & $* * *$ \\
\hline $\mathrm{R}^{2}$ não-ajustado $=0,0265878$ & & $\mathrm{R}^{2}$ ajustado $=0,0246371$ & \\
\hline
\end{tabular}

Fonte: Dados da pesquisa.

$\mathrm{Na}$ Tabela 5, são apresentados os resultados da regressão da equação (2), como se pode observar, todos os coeficientes apresentam significância elevada demonstrando que os valores médios do índice de Governança Corporativa para cada região são estatisticamente deferentes.

Tabela 5- Estimativas "Pooled OLS" variável depenndente GC

\begin{tabular}{|c|c|c|c|c|c|}
\hline Variável & Coeficiente & Erro Padrão & estatística- $t$ & p-valor & \\
\hline Região A & 50,1794 & 0,464875 & 107,9417 & $<0,00001$ & $* * *$ \\
\hline Região B & 40,0794 & 3,31625 & 12,0857 & $<0,00001$ & $* * *$ \\
\hline Região C & 56,3492 & 3,31625 & 16,9918 & $<0,00001$ & $* * *$ \\
\hline Região D & 57,9439 & 0,961782 & 60,2464 & $<0,00001$ & $* * *$ \\
\hline \multicolumn{3}{|c|}{$\mathrm{R}^{2}$ não-ajustado $=0,963757$} & \multirow{2}{*}{\multicolumn{3}{|c|}{$\mathrm{R}^{2}$ ajustado $=0,963574$}} \\
\hline \multicolumn{3}{|c|}{ Estatística-F $(4,591)=3928,95(p$-valor $<0,00001)$} & & & \\
\hline
\end{tabular}

Fonte: Dados da pesquisa.

A região $\mathrm{D}$ foi a que apresentou maior média (57,9439), seguida das regiões $\mathrm{C}$ $(56,3492)$, A $(50,1794)$ e, por último, B $(40,0794)$ evidenciando que, dentre as regiões pesquisadas, é onde as ações de Governança Corporativa são mais eficientes. Por conseguinte, ocorre com menor frequência a prática de manipulação de informação contábil no processo de mensuração de ativos a valor justo.

\section{Conclusão}

O estudo em pauta tem por objetivo verificar se a Governança Corporativa é um instrumento que inibe a prática de manipulação de informação contábil no processo de mensuração a valor justo dos ativos nos bancos comerciais. Para a realização da pesquisa, foi tomado como universo o conjunto de bancos comercias listados no Bloomberg databases. Como instrumento de análise empírico, foi utilizada a análise de regressão com dados em painel e a análise de correlação de Pearson.

A pesquisa mostra que ainda são poucos os bancos que divulgam em seus relatórios financeiros os ativos que são avaliados pelo valor justo, apesar de a norma recomendar não apenas a divulgação desses valores como também os critérios utilizados para sua determinação. Mesmo mercados maduros, como o da América do Norte e da Europa, apresentaram um número elevado de instituições que não cumprem o estabelecido no IFRS 7. Sendo a divulgação dessas informações um discluosure obrigatório, é de se esperar que a maioria dos bancos já estivesse com os seus relatórios financeiros de acordo com a norma. 
O resultado do estudo mostra que a Governança Corporativa exerce uma influência preponderante na escolha dos critérios de avaliação dos ativos a valor juto, evidenciando que quanto mais eficiente são as ações de fiscalização da Governança Corporativa maior são os ativos avaliados no Nível 1. Esse resultado mostra que as boas práticas de Governança Corporativa reduz o gerenciamento de resultado no processo de mensuração dos ativos a valor justo, corroborando as pesquisas anteriores. Os resultados ainda sugerem que a América Central (região B) é onde pode ocorrer com maior frequência a manipulação de informação contábil no processo de mensuração de ativos a valor justo, e a Europa (região D) é onde essa prática pode ocorrer com menor frequência.

\section{Referências}

AL-KHADASH, H. A.; ABDULLATIF, M. Consequences of Fair Value Accounting for Financial Instruments in the Developing Countries: The Case of the Banking Sector in Jordan. Jordan Journal of Business Administration, v. 5, n. 4, 2009.

BARROS, R. et al. A relação entre Governança Corporativa e gerenciamento de resultados em empresas brasileiras. Revista de Contabilidade e Organizações, v.19, 2013.

BHAT, G. Impact of Disclosure and Corporate Governance on the Association between Fair Value Gains and Losses and Stock Returns in the Commercial Banking Industry. Olin Business School, Washington University in St. Louis, 2013.

Disponível em: <http://papers.ssrn.com/sol3/papers.cfm?abstract_id=1013926> Acesso em: 14 jun. 2014.

BERGER, N. et al. The Roles of Corporate Governance in Bank Failures during the Recent Financial Crisis. December 2012.

Disponível em: <http://papers.ssrn.com/sol3/papers.cfm?abstract_id=304195>

Acesso em: 14 jun. 2014.

BLIKA, P.; SKODA, M. Fair Value Financias Statements - Advantage And Disadvantage. Studia Universitatis "Vasile Goldiş" Arad. Economics Series, v.22, Issue 2, 2012.

BRATTEN, B. et. al. Fair Value Accounting, Auditor Specialization, and Earnings Management: Evidence from the Banking Industry. March 2013.

Disponível em: <http://papers.ssrn.com/sol3/papers.cfm?abstract_id=2151635> Acesso em: 14 jun. 2014.

CHANG et. al. Earnings management and FAS 157, College of Business, Prairie View A\&M University, 2007.

Disponível em:

$<$ http://www.pvamu.edu/Include/College\%20of\%20Business/Faculty_pages/workingpapers/F AS\%20157\%202009.pdf>

Acesso em: 14 jun. 2014. 
CORNETT, M. et al. Corporate governance and earnings management at large U.S. bank holding companies. Journal of Corporate Finance, v. 15, n.5, p. 412-430, 2009.

CPC 40 - Instrumentos Financeiros: Evidenciação. Disponível em:

$<$ http://www.cpc.org.br/pdf/CPC40_final\%20_sem\%20marcas_\%2018julho2012.pdf $>$.

Acesso em: 6 jun. 2013.

CUPERTINO, C. M. Earning Management: Estudo de Caso do Banco Nacional. Revista Contabilidade \& Finanças, n. 41, p. 110-120. São Paulo, 2006.

DANTAS et. al. Gerenciamento de Resultados em Bancos com Uso de TVM: Validação de Modelo de Dois Estágios. R. Cont. Fin. - USP, São Paulo, v. 24, n. 61, p. 37-54, jan./fev./mar./abr. 2013.

DeANGELO, L. E. Accounting Numbers as Market Valuation Substitutes: A Study of Management Buyouts of Public Stockholders. The Accounting Review, p. 400-420. July1986.

DECHOW, P. et al. Causes and Consequences of Earnings Manipulation: an analysis of firms subject to enforcement actions by the SEC. Contemporary Accounting Research, Toronto, V. 13, No. 1, p. 1-36, Spring 1996.

DECHOW, M. P. et. al. Fair value accounting and gains from asset securitizations: A convenient earnings management tool with compensation side-benefits. Journal of Accounting and Economics, v. 49, p. 2-25. 2010.

DECHOW, P.M.; SKINNER, D. Earnings management: reconciling the views of accounting academics, practioners and regulators. Accounting Horizons, Sarasota, v. 4, n.2, p. 235-250. June 2000.

DeFOND, M.; JIMBALVO, J. Debt Covenant Violation and Manipulation of Accruals. Journal of Accounting and Economics, v.17, p.145-176. 1994.

ERFURTH, A.; BEZERRA, F. Gerenciamento de resultados nos diferentes níveis de governança corporativa. Base - Revista de Administração e Contabilidade da Unisinos, v. 10, n.1, p. 32-42, 2013.

FASB. Fasb Staff Position 157-4 - Fair Value Measurements, 2008. DispoNível em : <www.fasb.org.>. Acesso em: 6 jun. 2012.

FIECHTER, P.; MEYER, C. Discretionary Measurement of Financial Assets During the 2008 Financial Crisis. February 2011.

Disponível em: <http://papers.ssrn.com/sol3/papers.cfm?abstract_id=1522122>

Acesso em: 14 jun. 2014. 
FUJI, A. H. Gerenciamento de resultados contábeis no âmbito das instituições

financeiras atuantes no Brasil. São Paulo. Dissertação (Mestrado em Ciências Contábeis) Faculdade de Economia, Administração e Contabilidade da Universidade de São Paulo, 2004.

GABRIEL, F.; CORRAR, L. J. Gerenciamento de resultados e de Capital no sistema Bancário Brasileiro - Uma Investigação Empírica nas Aplicações em Títulos e Valores Mobiliários.

Revista de Contabilidade do Mestrado em Ciências Contábeis da UERJ (online), Rio de Janeiro, v. 15, n. 2, p. 49 - 62. maio/ago. 2010.

GALDI, F. C.; CÂMARA, G. A. Securitização Como Mecanismo de Gerenciamento de Resultados em Bancos Brasileiros. In: Encontro da ANPAD, XXXVI, 2012, Rio de Janeiro.

GALDI, F. C.; PEREIRA, L. M. Fair Value dos Derivativos e Gerenciamento de Resultados nos Bancos Brasileiros: Existe Manipulação? In: Encontro Brasileiro de Finanças, 7, 2007, São Paulo. Anais... São Paulo: Ibmec, 2007.

GEBHARDT, G. et. al. Financial Instruments Fair Value Accounting for (not against) the Banking Industry. Center for Financial studies No 2003/21.

GIL, A. Metodologia do Conhecimento Científico. São Paulo: Atlas, 2000.

GILLAN, S. L.; STARKS, L. T. A survey of shareholder activism: Motivation and empirical evidence. Contemporary Finance Digest, v.3, p. 10-34, 1998.

GONZALEZ, J.; MECA, E. Does Corporate Governance Influence Earnings Management in Latin American Markets? J Bus Ethics, v.121, p.419-440, 2014.

Disponível em: <http://link.springer.com/article/10.1007\%2Fs10551-013-1700-8\#page-1> Acessado em: 17 jun. 2014.

HEALY, P.; e WAHLEN, J. A Review of the Earnings Management Literature and its Implications for Standard Setting. Accounting Horizons, v. 13, n. 4, p. 365-383. 1999.

HEALY, P. The Effect of Bonus Schemes on Accounting Decisions. Journal of Accounting \& Economics, v.7, p. 85-107. 1985.

HUANG et al. Earnings management and FAS 157. College of Business, Prairie View A\&M University. 2009.

Disponível em:

$<$ http://www.pvamu.edu/Include/College\%20of\%20Business/Faculty_pages/workingpapers/F AS\%20157\%202009.pdf>

Acessado em: 17 jun. 2014.

IBGC. Código de Melhores Práticas de Governança Corporativa. 4. ed, 2010. Disponível em: <www.ibgc.org.br>. Acesso em: 02 dez. 2013. 
JONES, J. 1991, Earnings Management During Import Relief Investigations. Journal of Accounting Research, v. 29, p. 193-228. 1991.

KADOUS, K., KOONCE, L.; THAYER, J.M. Do Financial Statement Users Judge Relevance Based on Properties of Reliability?. The Accounting Review, V. 87, n. 4, p. 1335-1356, July 2012.

KARAOGLU, N. E. Regulatory Capital and Earnings Management in Banks: The Case of Loan Sales and Securitizations. Federal Deposit Insurance Corporation - Center for Financial Research, n. 2005-05.

KASZNIK, R. On the Association between Voluntary Disclosure and Earnings Management. Journal of Accounting Research, v. 37, n. 1, p. 57-81. Spring, 1999.

KING, A. F. Determining Fair Value The very essence of valuation is the professional judgmen of the appraiser, not just a set of rules. Strategic Finance, January 2009.

KRAFT, P. Fair value methodologies. Journal of Investment Compliance, v. 6 No. 1, p. 1622. 2005.

LAGHI, E. et al. Fair Value Hierarchy in Financial Instrument Disclosure. Is There Transparency For Investors? Evidence From The Banking Industry. Journal of Governance and Regulation, v. 1, Issue 4, 2012.

LEUZ et al. Investors protection and Earning Management: an international comparison.

Journal of Financial Economics, v. 69, n. 3, p.505-527, 2003.

MARTINEZ, A. L. Gerenciamento dos resultados contábeis: estudo empírico das companhias abertas brasileiras. Tese (Doutorado em Contabilidade), FEA-USP, São Paulo, 2001 .

MARTINEZ, A. Quando o Conselho de Administração e a Auditoria Evitam o Gerenciamento de Resultados? Evidencias Empírica Para Empresas Brasileiras. RIC Revista de Informação Contábil, v. 4, no 1, p 76-93, Jan-Mar/2010.

MARTINS, V.G. et al. Mensuração de Ativos Financeiros a Valor Justo: Análise da Relevância da Informação e da Confiabilidade da Mensuração na Perspectiva do Mercado Brasileiro de Capitais. In: CONGRESSO USP DE CONTABILIDADE E CONTROLADORIA, X III., 2013, São Paulo. Anais eletrônicos... São Paulo: 2013. Disponível em: $<$ http://www.congressousp.fipecafi.org/artigos132013/252.pdf $>$. Acesso em: 2 jun. 2013.

MONTEIRO, J.C.; GRATERON, I. R. G. Impacto de la aplicacion del fair value em la volatilidad de la banca brasileña: um estúdio empírico. Revista de Contabilidade e Finanças. USP. São Paulo, n.40, p. 102-119. 2006. 
OHRNY, E. Does Corporate Governance Induce Earnings Management? Evidence from Bonus Depreciation and the Fiscal Cliff. University of Michigan October, 2013. Disponível: http://www-personal.umich.edu/ ericohrn/jmp.pdf Acesso em: 14 jun. 2014.

PAULO, E. Manipulação das informações contábeis: uma analise teórica e empírica sobre os modelos operacionais de detecção de gerenciamento de resultados. 2007. Tese (Doutorado em Controladoria e Contabilidade) - Universidade de São Paulo: São Paulo, 2007.

PERLINGEIRO, B. Teoria das Escolhas Contábeis: Fair Value de Derivativos em Bancos no Brasil. São Paulo, 2009 (Dissertação de Mestrado Controladoria e Contabilidade) Faculdade de Economia, Administração e Contabilidade da Universidade de São Paulo.

PERRY, S. E.; WILLIAMS, T. H. Earnings Management Preceding Management Buyout Offers, Journal of Accounting and Economics, v 18, n.2, p. 157-179. 1994.

PICCOLI, P. et al. As práticas de Governança Corporativa diminuem o gerenciamento de resultados? Evidências a partir da aversão na divulgação de prejuízos e de queda nos lucros.

Revista Contemporânea de Contabilidade, v. 11, n. 22, p. 141-162, jan./abr. Santa Catarina 2014.

RAMOS, G.; MARTIINEZ, A. Governança Coorporativa e Gerenciamento de Resultados Contábeis. In: ENANPAD, 30 ${ }^{\circ}$ 2006, Salvador. Anais... CD-ROM 3120.

RANGEL, L.A.; ANDRADE, G. A Aplicação da Governança Corporativa como Instrumento de Redução do Gerenciamento de Resultados nas Empresas de Capital Aberto. II Simpósio de Excelência em Gestão e Tecnologia - SEGeT'2005. Disponível em:

$<$ http://www.aedb.br/seget/artigos05/251_A \%20Aplicacao\%20da\%20GC\%20como\%20instru mento $\% 20 \mathrm{de} \% 20$ reducao $\% 20 \mathrm{do} \% 20 \mathrm{GR} \% 20$ nas $\% 20$ Empresas\%20de $\% 20$ Capital\%20Aberto. pdf>. Acesso em: 13 dez. 2013.

RESENDE, G.; e NAKAO, S. Gerenciamento de Resultados e a Relação Com o Lucro Tributável das Empresas, Revista Universo Contábil, v. 8, n. 1, p. 6-21. Blumenau, 2012.

RODRIGUES, A.; PAULO, E.; CARVALHO, L. N. Gerenciamento de resultados por meio das transações entre companhias brasileiras interligadas. Revista de Administração da USP - RAUSP, v. 42, n. 2, p. 216-226. 2007.

SANTOS, P. et al. Gerenciamento de Resultados por Meios de Decisões Operacionais e a Governança Corporativa: Analise das Industrias Siderúrgicas e Metalúrgicas Brasileiras. Revista de Contabilidade e Organizações, v. 5 n. 13 (2011) p. 55-74

SCHIPPER, K. Commentary on earnings management. Accounting Horizons, p. 91-102. December, 1989. 
SHAH, S. et al. Corporate Governance and Earnings Management an Empirical Evidence Form Pakistani Listed Companies. European Journal of Scientific Research, V.26, n.4, p.624-638, 2009.

SHLEIFER, A.; VISHNY, R. A survey of corporate governance. Journal of Finance, v. 52, n. 2, p. 737-783, June, 1997.

SILVEIRA, A. D. M. et al; Fair Value in Financial Statements - advantages And Disadvantages. Studia Universitatis "Vasile Goldiş" Arad Economics Series, V. 22, Issue 2, 2012.

SONG, M.; LEI, H. Corporate Governance, Family Ownership, and Firm Valuations in Emerging Markets: Evidence from Hong Kong. March, 2008. Disponível em: < http://papers.ssrn.com/sol3/papers.cfm?abstract_id=1100710> Acesso em: 14 jun. 2014.

SONG, C. et al. Value Relevance of FAS 157 Fair Value Hierarchy Information and the Impact of Corporate Governance Mechanisms. Forthcoming in The Accounting Review (July 2010). Disponível em:

$<$ http://papers.ssrn.com/sol3/papers.cfm?abstract_id=1198142>

Acesso em: 14 jun. 2014.

SONG, C. J. An Evaluation of FAS 159 Fair Value Option: Evidence from the Banking Industry. September 2008. Disponível em: $<$ http://ssrn.com/abstract=1279502>. Acesso em: 2 jun. 2013.

SPENCE, M. Job Market Signaling, The Quarterly Journal of Economics, v. 87, n. 3, p. 355-374. 1973.

STEPHEN H. Financial reporting quality: is fair value a plus or a minus? Accounting and Business Research. Special Issue: International Accounting Policy Forum. p. 33-44. 2007.

SUNDER, S. Theory of accounting and Control. Cincinnati, OH: South-Westen College Publishing 1997.

TEOH, S. H.; WELCH, I.; WONG, T. J. Earnings Management and the Long-Run Market Performance of Initial Public Offerings. The Journal of Finance, v. 53, n. 6, p. 1935-1974, 1998.

UMBELINO, W. S. et al. Evidenciação do valor justo das instituições financeiras de capital aberto da Bovespa. I SEMINÁRIO UFPE DE CIÊNCIAS CONTÁBEIS, 17 a 19/09/2007. Disponível em:

$<$ http://www.controladoria.ufpe.br/anais2007/arquivos/Area\%20Tematica\%20(b)/2.pdf> Acesso em: 14 jun. 2014. 
XAVIER, P. H. Gerenciamento de resultados por bancos comerciais no Brasil. São Paulo, 2007. Tese (Doutorado em Controladoria e Contabilidade) - Faculdade de Economia, Administração e Contabilidade da Universidade de São Paulo.

XIE, B.; DADAIF, P. Earning Management and Corporate Governance: The Roles of The Audit Committee. July 5, 2001

DispoNível em: $<$ http://papers.ssrn.com/sol3/papers.cfm?abstract_id=304195> Acesso em: 14 jun. 2014.

ZENDERSKY, H. C. Gerenciamento de resultados em instituições financeiras no Brasil 2000 a 2004. Brasília, 2005. Dissertação (Mestrado em Ciências Contábeis) - Programa Multiinstitucional e Inter- Regional de Pós-Graduação em Ciências Contábeis da Universidade de Brasília, Brasília.

ZINGALES, L. Corporate Governance. The New Palgrave Dictionary of Economics and the Law, Working Paper Series, June, 1998. 